\title{
Grain Quality Assessment of Scented and Non Scented Rice Varieties under Organic Nutrient Management
}

\author{
Mahendra Anjna ${ }^{1}$, V. K. Shukla ${ }^{1}$, S. S. Shukla ${ }^{2}$ and Shivam Gour ${ }^{3}$ \\ ${ }^{1}$ Department of Agronomy, College of Agriculture Jabalpur, Jawaharlal Nehru Krishi Vishwa \\ Vidyalaya, Jabalpur (MP) - 482004, India \\ ${ }^{2}$ Department of Food Science and Technology, JNKVV, Jabalpur (MP), India \\ ${ }^{3}$ College Of Agriculture Indore, Rajmata Vijayaraje Scindia Krishi Vishwavidyalaya, \\ Gwalior, (MP)-452001, India \\ *Corresponding author
}

Keywords

Physico-chemical, Milled rice, Hulling, Alkali spreading value Scented Rice and Non-scented rice.

\section{Article Info} Accepted: 12 August 2019 Available Online: 10 September 2019
Global demand for organically grown foods is increasing and organic agriculture is growing fast in recent years. Organic farming encourages the reduction of agrochemicals and promotes soil conservation principles. Field experiment was conducted at Krishi Nagar, Research Farm, Jawaharlal Nehru Krishi Vishwa Vidyalaya, Jabalpur (MP) during kharif season 2018. Experiment was carried out using randomized complete block design involving twelve scented and non scented rice (Oryza sativa L.) varieties with three replications. An improved scented varieties viz., Pusa Sugandha 5, Pusa Sugandha 4, Pusa Sugandha 3, Pusa Basmati 1, Madhumati \& Sahyadri and non scented varieties viz., BVD 109, JR 201, Dhanteshwari, IR 36, MTU 1010 \& IR 64 were included as a test variety. A uniform dose of organic manures i.e. $1 / 3^{\text {rd }}$ Nitrogen through each of Farm yard manure, Neem cake and Vermicompost were applied to all the varieties. Results of the study revealed that Pusa Sugandha 3 has recorded significantly higher grain yield (3298 $\mathrm{kg} \mathrm{ha}^{-1}$ ) among all the varieties. Pusa Sugandha 5 recorded maximum Physico-chemical quality parameters viz., Paddy length- breadth ratio (5.21), Milled rice L: B ratio (7.23), Hulling per cent (76.80\%), Milling per cent (67.90\%), Head Rice Recovery (59.94\%), Alkali spreading value (6.67) and Elongation ratio (1.95) fallowed by Pusa Sugandha 4 and Pusa Sugandha 3 . The minimum grain quality parameters were recorded in non scented rice varieties. 


\section{Introduction}

Rice (Oryza sativa L.) is one of the most important cereal crops of the world, grown in different areas over the world. It is grown in more than hundred countries, with a total area of 158 million hectares, producing more than 700 million tonnes (MT) annually. India is not only a leading consumer of rice crop but also its second largest producer in the world (115.60 million tonnes), lagging behind only China. In India total area under rice cultivation is 43.86 million ha. and rice is grown in almost half the states, with West Bengal leading the way in terms of production with 15.75 million tonnes, followed by Uttar Pradesh (12.22 million tonnes) and Punjab (11.57 million tonnes) as per the Agricultural Statistics 2018-19, Ministry of Agriculture \& Farmers Welfare of the Government of India. In Madhya Pradesh, rice is grown in around 2.02 million ha area with the production of $3.58 \mathrm{MT}$ and with average yield of $1768 \mathrm{~kg} / \mathrm{ha}$ (Agriculture research data book, 2017). India has earned more than Rs 18,000 crore foreign exchange per year from the export of basmati rice; especially from the variety Basmati rice developed by the country's top agri-institute ICAR. Organic farming is gaining momentum during recent times due to awareness of people towards environment and food safety. Production of high quality organic aromatic rice by the farmers for domestic as well as export purpose is a major concern of future agricultural strategy. Organic food markets in India are expanding quite fast owing to growing demand for organic food and the high premium it fetches (Patnaik, 1996). Basmati and fine grain aromatic rice have tremendous export value. Organic and inorganic produce differ in quality parameters (Artur and Kjellenberg, 1997; Bourn and Prescott, 2002; Wszelaki et al., 2005). Basmati rice commands high premium in market due to its exclusive nature and quality traits such as linear kernel elongation with least breadth- wise swelling, intensity of aroma, fluffiness, palatability and longer shelf life. Scented rice has a special place in the world rice market and is generally the highest priced rice (Efferson, 1985). Aromatic rice has great potential to attract rice consumer for its taste and deliciousness, and high price to boost up the economic condition of the rice grower in the country. Because of its natural chemical compounds which give it a distinctive scent or aroma when cooked, aromatic rice commands a higher price than non- aromatic rice. (Singh et al., 2001). Kernel shape and L/B ratio are important features for grain quality assessment (Rita and Sarawgi, 2008). Aroma, hardness and roughness are depends on temperature and variety specific which affects the sensory properties of cooked rice (Yau and Huang, 1996) The present investigation was therefore, undertaken to Grain quality assessment of scented and non scented rice varieties under organic nutrient management.

\section{Materials and Methods}

The experiment was conducted at Krishi Nagar, Research Farm, Jawaharlal Nehru Krishi Vishwa Vidyalaya, Jabalpur (MP) during kharif season 2018. The soil of the experimental site was neutral in reaction $(\mathrm{pH}$ 7.27) with normal EC $\left(0.36 \mathrm{dS} \mathrm{m}^{-1}\right)$, medium in OC contents $(0.84 \%)$, low in available $\mathrm{N}$ $\left(267.83 \mathrm{~kg} \mathrm{ha}^{-1}\right)$, medium in available $\mathrm{P}(12.96$ $\left.\mathrm{kg} \mathrm{ha}^{-1}\right)$, and medium in available K (300.03 $\mathrm{kg} \mathrm{h} \mathrm{h}^{-1}$ ) contents. The rainfall was less $1092.10 \mathrm{~mm}$ and other weather conditions were normal for better growth and development of the crop. The treatments consisted of twelve varieties of rice were divided into two groups scented and non scented. Scented varieties viz., Pusa Sugandha 5, Pusa Sugandha 4, Pusa Sugandha 3, Pusa Basmati 1, Madhumati \& Sahyadri and non scented varieties viz., BVD 109, JR 201, Dhanteshwari, IR 36, MTU 1010 \& IR 64 were tested in randomized block design with 
three replications. A uniform dose of organic manures i.e. $1 / 3^{\text {rd }} \mathrm{N}$ through each of FYM, Neem cake and Vermicompost and rock phosphate were applied to all varieties. Organic manures were applied based on their nutrient content and incorporated two weeks before planting. Twenty days old seedlings were transplanted on $10^{\text {th }}$ July 2018 by using of two seedlings per hill with the planting geometry of $20 \mathrm{~cm} \times 20 \mathrm{~cm}$. Weeds were controlled by two hands weeding at 20 and 40 days after transplanting (DAT).Yield parameters were recorded along with grain and straw yield. Quality tests of grain viz., length and breadth of paddy, brown rice and milled rice, hulling, milling and head recovery were done by using a composite sample in thrice replication. The observations were recorded and techniques were employed in present investigation are summarized as under:

The length and breadth of ten randomly selected paddy, brown rice and milled rice kernels were measured with the help of a graph paper or screw gauge. Average of length and breadth was taken in millimeters and Length- Breadth ratio (L: B ratio) was calculated (Dela Cruz and Khush, 2000).

\section{Hulling percentage}

The mud lumps, rice stems, leaves and other foreign matter from the sample were removed and then $100 \mathrm{~g}$ of grain sample was weighed. The clean sample was shelled with the Satake Sheller. The samples were hulled and weights of de-hulled grains were recorded. The formula is as follows Hulling percentage-

$$
=\frac{\text { weight of brown rice (g) }}{\text { weight of paddy(g) }} \times 100
$$

\section{Milling percentage}

The hulled samples were milled and weight of milled grains was recorded. The formula is as follow;
Milling percentage

$=\frac{\text { weight of milled rice }(\mathrm{g})}{\text { weight of paddy }(\mathrm{g})} \times 100$

\section{Head rice recovery percentage}

After milling the whole and broken grains were separated. The per cent of head rice or unbroken rice grain were determined based on the initial weight of the rough rice per cent of total rice or sum total of head rice and all classes of broken rice. The formula is as follow

Head rice recovery percentage

$=\frac{\text { Weight of head polished rice(g) }}{\text { Weight of milled rice(g) }} 100$

\section{Determination of aroma}

Aroma content was estimated by using method developed by IRRI (1971) and subsequently improved by Sood and Siddiq (1978).

The method consists of adding about $10 \mathrm{ml}$ of 1.7 per cent potassium hydroxide solution to a small petri plate containing about 2 g finely minced sample of grain. Then petri plates are covered immediately after addition of alkali and left at room temperature for about 10 minutes. The plates are then opened and the contents smelled. The samples possessing the scent as one could easily feel, produce a sharp and readily recognizable aroma.

$\mathrm{SS}=$ strongly scented; MS = mild scented; NS $=$ non scented

\section{Alkali spreading value (Gelatinization temperature)}

The Gelatinization temperature was measured in terms of alkali disintegration using a (7) point numerical spreading scale as suggested 
by Little et al., (1958). Six milled rice kernels were evenly placed in Petridis containing 1.7 per cent $10 \mathrm{ml} \mathrm{KOH}$ solution at $30 \pm 1^{\circ} \mathrm{C}$ for 23 hours and the scoring was recorded.

\section{Elongation ratio}

Elongation ratio (ER) of cooked kernels was determined by dividing the length of cooked kernel to length of uncooked kernel (Juliano and Betchel, 1985). This was calculated by the following formula:

Elongation ratio

$=\frac{\text { Length of cooked kernel }(\mathrm{mm})}{\text { Length of raw } \operatorname{kernel}(\mathrm{mm})}$

Data collected and recorded from various observations were tabulated and subjected to their statistical analysis as per the procedure suggested by Panse and Sukhatme (1967).

\section{Results and Discussion}

Data pertaining to grain quality parameters were presented in table 1. Among the different varieties, paddy length was widely ranged from 12.33 to $6.33 \mathrm{~mm}$. The significantly highest paddy length $(12.33 \mathrm{~mm})$ measured in the Pusa Sugandha 5 which was significantly superior over other varieties of rice. The lowest paddy length $(6.33 \mathrm{~mm})$ was measured for the variety JR 201. Paddy breadth of rice varieties there were no significant difference among the all varieties. Paddy length- breadth ratio (L: B ratio) varied significantly for different rice varieties and ranged from 5.21 to 2.33. Pusa Sugandha 5 calculated significantly highest L: B ratio (5.21) which was at par with Pusa Sugandha 4 and Pusa Sugandha 3. The lowest L: B ratio (2.33) was calculated under variety JR 201.

The length and breadth of dehulled rice of all the varieties were measured (Table 1) and brown rice length ranged from 8.53 to 5.63 $\mathrm{mm}$. Brown rice $\mathrm{L}$ : $\mathrm{B}$ ratio of different rice varieties greatly varied from 4.59 to 2.37 .

The length and breadth of white rice (milled rice) of all the varieties were measured, length ranged from 7.23 to $4.87 \mathrm{~mm}$ amongst the varieties. The significantly highest milled rice length $(7.23 \mathrm{~mm})$ measured in the Pusa Sugandha 5 which was significantly superior over other varieties of rice except Pusa Sugandha 4 and Pusa Sugandha 3. The lowest milled rice length $(4.87 \mathrm{~mm})$ was measured for the variety JR 201. L: B ratio of different milled rice varieties greatly varied from 4.16 to 2.25 with highest value (4.16) for Pusa Sugandha 5 which was at par with Pusa Sugandha 4 (3.92) and Pusa Sugandha 3 (3.77). The lowest value of milled rice L: B ratio was calculated in JR 201 (2.25).

Data on hulling percentage are presented in table 2. All the varieties had average 72.90 (\%) hulling percent and ranged from 76.80 to 66.63 per cent for different rice varieties. The highest hulling percentage was calculated in Pusa Sugandha $5(76.80 \%)$ which was at par with Pusa Sugandha 4, Pusa Sugandha 3, Dhanteshwari, Madhumati and Pusa Basmati 1 .

The lowest hulling percentage was calculated in Sahyadri (66.63\%). Variation in hulling percentage may be due to differences in genetic potential and moisture content. Similar findings have also been reported by Subudhi et al., (2012). 
Int.J.Curr.Microbiol.App.Sci (2019) 8(9): 775-782

Table.1 Physical quality parameters of scented and non scented rice varieties under organic nutrient management

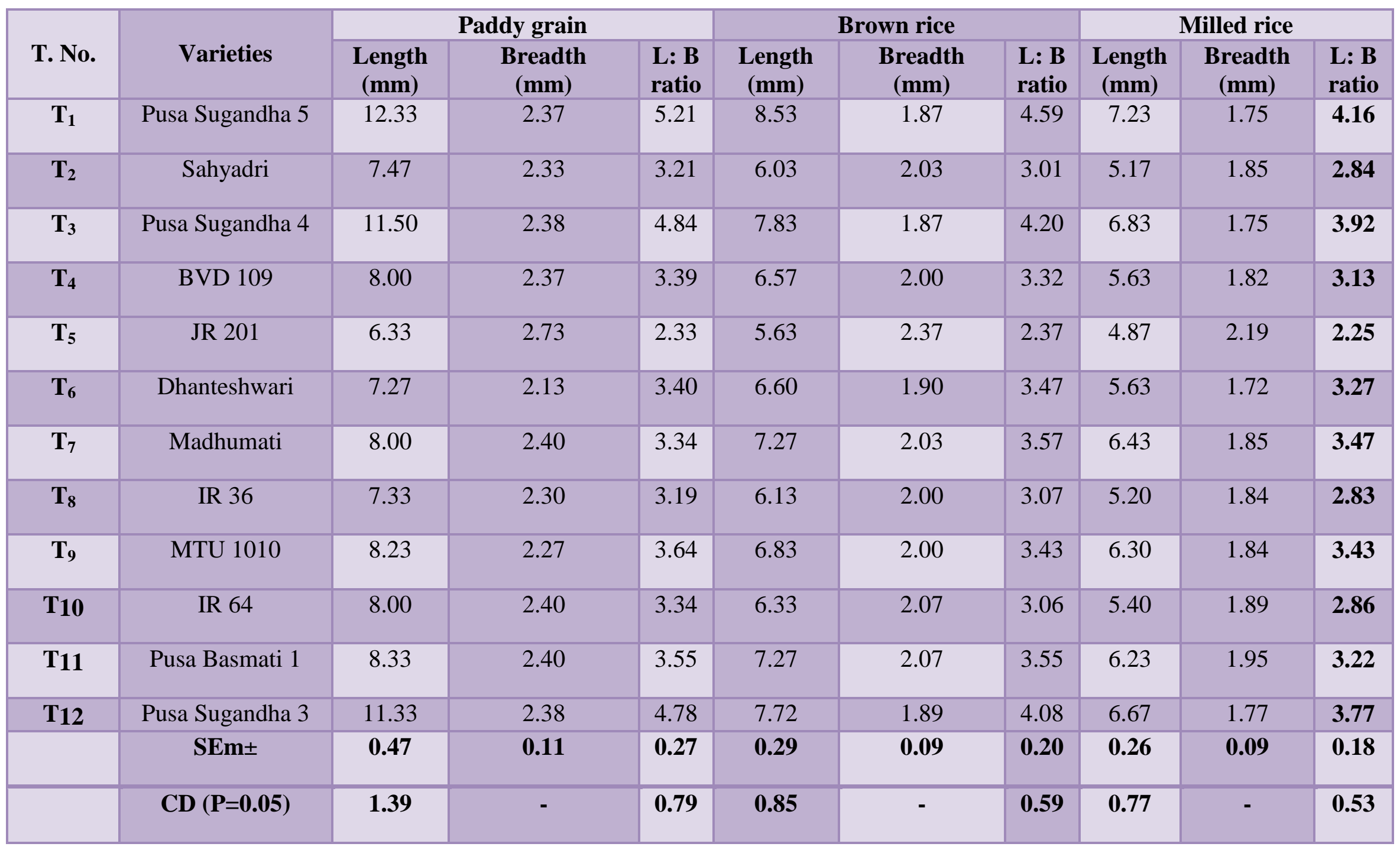


Table.2 Physico-chemical parameters of scented and non scented rice varieties under organic nutrient management

\begin{tabular}{|c|c|c|c|c|c|c|c|}
\hline T.No. & Varieties & $\begin{array}{c}\text { Hulling } \\
(\%)\end{array}$ & Milling (\%) & $\begin{array}{c}\text { Head rice } \\
\text { recovery }(\%)\end{array}$ & $\begin{array}{c}\text { Alkali } \\
\text { spreading } \\
\text { value }\end{array}$ & $\begin{array}{c}\text { Elongation } \\
\text { ratio }\end{array}$ & $\begin{array}{l}\text { Grain yield } \\
\quad\left(\mathrm{kg} \mathrm{ha}^{-1}\right)\end{array}$ \\
\hline $\mathbf{T}_{1}$ & Pusa Sugandha 5 & 76.80 & 67.90 & 59.94 & 6.67 & 1.95 & 3082 \\
\hline $\mathbf{T}_{2}$ & Sahyadri & 66.63 & 59.31 & 51.82 & 4.67 & 1.78 & 2691 \\
\hline $\mathbf{T}_{3}$ & Pusa Sugandha 4 & 75.73 & 67.39 & 56.99 & 5.67 & 1.94 & 2986 \\
\hline $\mathbf{T}_{4}$ & BVD 109 & 67.13 & 64.39 & 51.66 & 4.67 & 1.77 & 2916 \\
\hline $\mathbf{T}_{5}$ & JR 201 & 71.17 & 63.71 & 52.63 & 4.33 & 1.74 & 2750 \\
\hline $\mathbf{T}_{6}$ & Dhanteshwari & 75.10 & 60.07 & 53.66 & 1.33 & 1.74 & 2796 \\
\hline $\mathbf{T}_{7}$ & Madhumati & 75.03 & 65.14 & 52.46 & 1.67 & 1.80 & 2535 \\
\hline $\mathbf{T}_{8}$ & IR 36 & 71.13 & 64.02 & 48.64 & 2.00 & 1.51 & 2774 \\
\hline $\mathbf{T}_{9}$ & MTU 1010 & 73.80 & 62.92 & 52.05 & 1.67 & 1.68 & 2845 \\
\hline T10 & IR 64 & 72.57 & 62.91 & 49.07 & 1.67 & 1.44 & 2786 \\
\hline T11 & Pusa Basmati 1 & 74.27 & 63.98 & 52.24 & 5.67 & 1.74 & 2823 \\
\hline \multirow[t]{3}{*}{ T12 } & Pusa Sugandha 3 & 75.40 & 66.69 & 54.06 & 4.67 & 1.81 & 3298 \\
\hline & SEm \pm & 1.20 & 0.12 & 1.45 & 0.33 & 0.07 & 37.23 \\
\hline & $\mathrm{CD}(\mathrm{P}=0.05)$ & 3.53 & 0.36 & 4.26 & 0.98 & 0.19 & 109.74 \\
\hline
\end{tabular}


Milling percent of all rice varieties (Table 2) differed significantly and ranged between $67.90(\%)$ to $59.31(\%)$ among the varieties. Significantly highest milling percentage was calculated in Pusa Sugandha 5 (67.90\%) followed by Pusa Sugandha 4.

The lowest milling percentage was calculated in Sahyadri (59.31\%). The head rice recovery of the varieties was calculated in table 2 and it was clear that all the rice varieties showed a significant difference with each other in terms of head rice recovery.

Maximum head rice recovery (59.94\%) was calculated in Pusa Sugandha 5 whereas minimum head rice recovery calculated in IR $36(48.64 \%)$.

Variation in head rice recovery in different varieties is closely related with moisture content and force of the milling machine. Similar results were recorded by Babu et al., (2013).

Aroma in rice was influenced by genetic character of variety and it is a very important character judging rice quality around the world. Characteristics pertaining to aroma in rice quality of scented rice varieties it was observed that only three varieties are strongly scented class of aroma and those were Pusa Sugandha 5, Pusa Sugandha 4 along with Pusa Sugandha 3, three varieties are mildly scented viz., Pusa Basmati1, Madhumati and Sahyadri whereas, rest of the rice varieties were found to be non scented viz., BVD 109, JR 201, Dhanteshwari, MTU 1010, IR 64 and IR 36. Nadaf et al., 2007 reported that Basmati rice contains more aroma than the traditionally cultivated scented rice varieties.

Gelatinization temperature (GT) of rice is measured in terms of alkali spreading value (ASV). The data on alkali spreading value are presented in Table 2.
It ranged from 1.33 to 6.67 . Pusa Sugandha 5 scored the highest alkali spreading value (6.67) which was found to be significantly superior over rest of the varieties except Pusa Sugandha 4 and Pusa Sugandha 3.

All the twelve rice varieties significantly varied with each other in length and breadth of rice kernel after cooking. Elongation ratio of different rice varieties (Table 2) ranged from 1.44 to 1.95 . Pusa Sugandha 5 calculated the highest elongation ratio (1.95) closely followed by Pusa Sugandha 4, Pusa Sugandha 3 and Madhumati. The least elongation ratio was calculated in IR 64 (1.44) which was comparable with IR 36 (1.51). The results of the present investigation unveil that evolved scented varieties were better than non scented varieties. Pusa Sugandha 3 proved better as compared to Pusa Sugandha 5 and Pusa Sugandha 4 especially in terms of grain yield. Pusa Sugandha 5 and Pusa Sugandha 4 varieties were mostly superior in quality parameters to non scented varieties. Hence, using easily available local natural resources, organic farming can be practiced with a view to protect/preserve/safe guard our own natural resources and environment for a fertile soil, healthy crop and quality food and let our future generations enjoy the benefits of nonchemical agriculture.

\section{References}

Agriculture research data book. 2017. ICARIndian Agricultural Statistics Research Institute (IASRI) New Delhi. 177-178 p.

Bajpai A, Singh Yogendra (2010). Study of quality characteristics of some small and medium grained aromatic rice of Uttar Pradesh and Uttarakhand. Agric.Sci.Digest. 30 (04): 241-245

Banerjee S, Ghosh M, Pal SK, Mazumdar D and Mahata D. 2015. Effect of organic nutrient management practices on 
yield and economics of scented rice gobindabhog.Oryza 50(4) 365-369.

Bhonsle SJ and Mondal SS. 2010. Grain quality Evalution and organoleptic analysis of aromatic rice varieties of Goa, India. Journal of Agriculture Sciences (Toronto), 2 (3): 99-107. 24ref.

Bhattacharya KR and Sowbhagya CM. 1972. Evaluation of alkali spreading value in rice. Cereal Sci. Today. 16: 420 - 424.

Davari MS and Sharma SN. 2010. Effect of different combination of organic materials and biofertilizerson productivity, grain quality and economics in organic farming of basmati (Oryza sativa). Indian Journal of Agronomy 55(3): 290-294.

Delacruz NM and Khush GS. 2000. Rice grain quality evaluation procedures. In: Aromatic Rices (Singh R K, Singh U S, and Khush G S, Eds.). Oxford \& IBH Publishing Co, New Delhi. 15-28.

Efferson JN. 1985. Rice quality in world markets. In: Grain quality and marketing. Paper presented at the International Rice Research Conference, 1-5 June 1985. p 1- 29.

Jennings PR, Coffman WR, Kauffman HE. 1979. Grain quality. In: Rice improvement.

Juliano BO, Bautista GM, Lugay JC, Reyes AC. 1964. Studies on the physicochemical properties of rice. J. Agric. Food Chem. 12:131-138.
Khush GS, Paule CM, de la Cruz NM. 1979. Rice grain quality evaluation and improvement at IRRI. In:Proceedings of Workshop on Chemical Aspects of Rice Grain Quality. Los Baños (Philippines): International Rice Research Institute. p 22-31.

Los Baños (Philippines): International Rice Research Institute. p 101-120.

Little RR, Hilder GB, Dawson EH. 1958. Differential effect of dilute alkali on 25 varieties of milled white rice.Cereal Chem. 35:111-126.

Nene YL. 1998. Basmati rice: a distinct variety (cultivar) of the Indian subcontinent. Asian-Agri-History, 2 (3): 175-188.

Shilpa J. 2010. Grain Quality Evaluation and Organoleptic Analysis of Aromatic Rice Varieties of Goa, India. Journal of Agricultural Science Vol. 2, No. 3

Singh V, Singh AK, Mohapatra T, Krishnan GS and Ellur RK. 2018. Pusa Basmati 1121 - a rice variety with exceptional kernel elongation and volume expansion after cooking. Journal of Agricultural Science 11:19

Sood BC and Siddiq EA. 1978. A rapid technique forscent determination in rice. Indian J. Genet. Plant Breed. 38: 268-271

Singh SK, Varma SC, Singh RP. 2001. Effect of integrated nutrient supply on growth, yield, nutrient uptake, economics and soil fertility in irrigated rice. Oryza. 2001; 38(1\&2):56-60.

\section{How to cite this article:}

Mahendra Anjna, V. K. Shukla, S. S. Shukla and Shivam Gour 2019. Grain Quality Assessment of Scented and Non Scented Rice Varieties under Organic Nutrient Management. Int.J.Curr.Microbiol.App.Sci. 8(09): 775-782. doi: https://doi.org/10.20546/ijcmas.2019.809.093 